\title{
Managing Viagers Securitization and Life Extension Risk
}

Charles A. Stone

Paris-Dauphine University zfinance@interserv.com
Anne Zissu

Temple University

zissu@sprynet.com

It is possible in France to finance the purchase of a property with a viager as opposed to a traditional mortgage, where the purchase pice of the property, or balance of the price, if a down payment is made (the bouquet), is converted into an annuity that the buyer agrees to pay for the remainder of the seller's life. Insurance companies in France have been significant investors in the viager market for many years. The cash flows generated by pools of viagers can mirror those from pools of life insurance policies. We propose a model that values the possible securitization of viagers, and that values life extension risk. The securitization of viagers gives insurance companies the opportunity to create portfolios where mortality risk can be hedged by life extension risk.

\section{INTRODUCTION}

In U.S. senior citizens can obtain financing via reverse mortgages, senior life settlements, accelerated death benefits, but not via a viager. The viager ${ }^{1}$ is a French financial contract. Senior lfe settlements are similar to viaticles in the sense that both viators (insured with terminal disease) and life settlers (insured with a life expectancy of ten years or less because of age) sell their life insurance policy at a discount from face value of benefits. Viators and life settlers sell an asset, the life insurance policy, at a discount from face value, with the remaining premia paid by the new owner of the life policy. The new owner of the policy becomes the beneficiary. A viager is a sale with a life annuity: the seller agrees to transfer the ownership of a property to the buyer (or investor) who commits to paying an agreed price. The ma in difference to the classic property's sale is that the amount is not paid fully on completion. The purchase pice, or balance of the price, if a down payment was made (the bouquet), is converted into an annuity that the buyer agrees to pay for the remainder of the seller's life, the annuitant. The annuitant continues to live in such property until the end of his life. Several state regulators in the U.S. have applied the model legislation issued by the National Association of Insurance Commissioners (NIAC) to viaticles and senior life settlements, see Bhattacharga J., Goldman D. and Sood N. (2004). The viager is a free market, it is not regulated. The amount of the annuity is freely agreed between the buyer and the seller, and is a function of the age of the annuitant, and of the initial bouquet, (Prettys Solicitors, June 2004).

Homeowners with a reverse mortgage, viators, life settlers and annuitants from viagers, all receive a zero or positive lump sum at the time of the transaction, followed by an annuity that expires at death. They all benefit financially the bnger they live. Their

\footnotetext{
${ }^{1}$ The word viager comes from viaje, which in old French means "time of life" (temps de vie).
} 
counterparties must manage this longevity risk. Longevity risk and the introduction of securitization as a mean of shifting/redistributing such risk to different parties are addressed by Lin \& Cox (2005). They propose mortality-based securities, such as mortality bonds and develop a model to price the proposed mortality securities. Milevsky (2005) develops an Index for Life Annuities, to eliminate the "abstract-sounding longevity insurance" and to obtain "more concrete and measurable financial rates of return". Doherty and Schlesinger (2002), and Cummins (2004) develop the concept of securitizing life insurance products in order to redistribute various risks specific to these products, to different groups of investors. Cowley \& Cummins (2005) address the possibility of shifting longevity risks to investors via securitization. Stone \& Zissu (2006) analyze the securitization of senior life settlements and propose a new security, the suredeath-class (SDS), a class that protects investors against longevity risk. They also introduce a new measurement of longevity risk for securitized pools of senior life settlements, the LE-duration (Life-Extension-Duration). The LE-duration measures the percentage change in value of a securitized pool of life settlements given a change in life expectancy for such pool.

We propose to securitize pools of viagers (we describe the French viager in the appendix) and value them by adapting the Stone \& Zissu model (2006). Lin and Cox (2005) write "It is not enough to estimate a mortality table and then estimate the expected value. The approach would ignore the uncertainty in the table." They value bonds with longevity risk under different simulated mortality shock and demonstrate how sensitive these securities are to changes in expected mortality. Using the Stone \& Zissu's LE-duration, we estimate the longevity risk of securitized pools of viagers and their sensitivity to shifts in expected mortality tables. We conclude the paper by introducing the concept of a self-hedged portfolio, containing both mortality risk and extension life risk (or longevity risk), a product of great interest to insurance companies.

\section{CASH FLOW ESTIMATION FOR VIAGERS}

There are two parties in the contract of a viager, the seller and the acquirer. The viager is a form of investment for many acquirers and insurance companies have been particularly active in this market, maybe as a possible hedge for life insurance policies they issue to individuals. The acquirer has a stream of negative cashflows, the bouquet at $t=0$ and the mortgage payments during the life of the seller, and then a positive cash flow obtained from the sale of the property at the time of death of the seller (the buyer has the option of not selling the property and to move in it, but this would be unlikely in the case of an insurance company).

In January 2004 a $\$ 63$ Million of class A senior life settlement securitization backed by $\$ 195$ million in face value of life insurance policies was issued by Tarrytown Second, LLC. This was the first securitization of senior life settlements issued in the U.S. market. The second senior life settlement securitization transaction, for an amount of \$70 million was issued in April 2004 by Legacy Benefits as a private placement. We expect in the near future that insurance companies will use securitization to finance their investments 
$d_{217}, \ldots . ., d_{225}=2 /(225-216)=.22222$

The results from Exhibit 2 show that the pool is expected to have a death rate $d$ of $.02778 \%$ each month for the first 36 months; a death rate of $.3333 \%$ from month 37 to month $72 ; .83333 \%$ from month 73 to month 108 , etc.

The rate of death based on the "Typical Distribution of Life Expectancies" (which we call scenario 1 throughout the paper) is graphed in Exhibit 3.

Exhibit 3: Annuitants' Death rate over time based on "Typical Distribution of Life Expectancies"

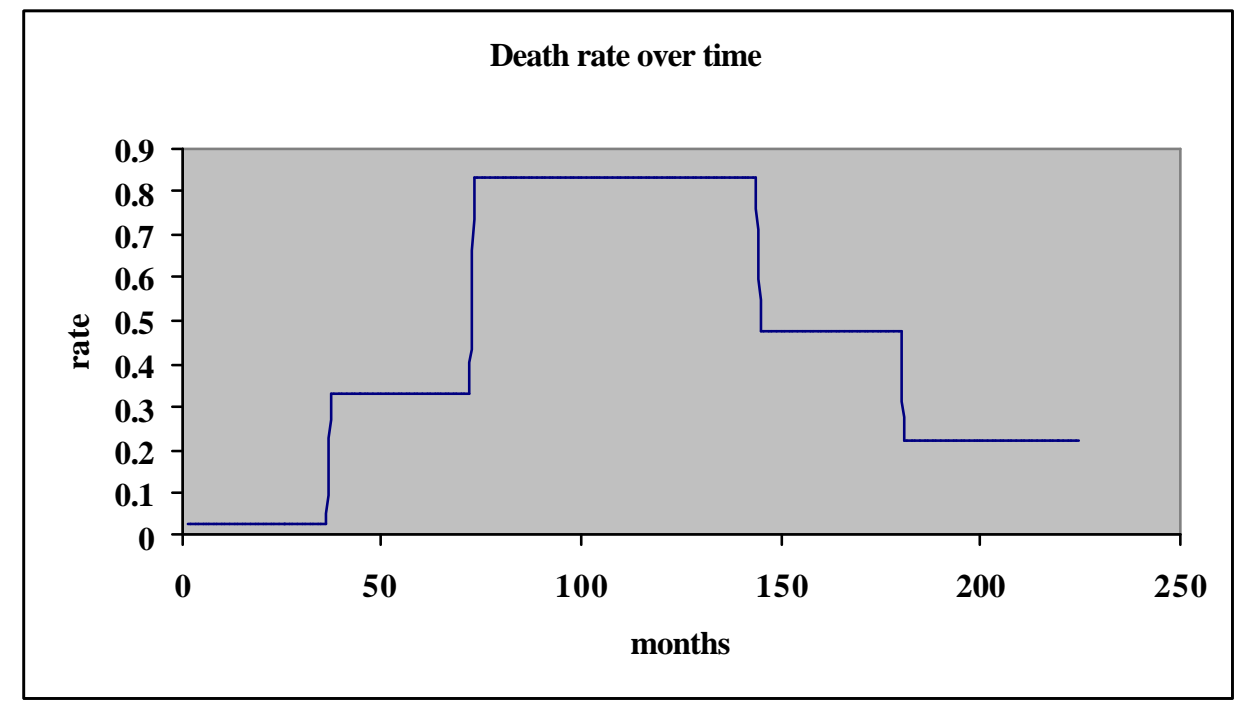

Exhibit 4 graphs the death rate over time under different scenarios. Scenario 1 is the base case, with "Typical Distribution of Life Expectancies"; scenario 2 shifts the distribution of the death rate in scenario 1 by twelve months (life extension by twelve months relative to the base case). Each subsequent scenario shifts/extends the distribution of the annuitants' death rate by another twelve months.

\section{Exhibit 4}




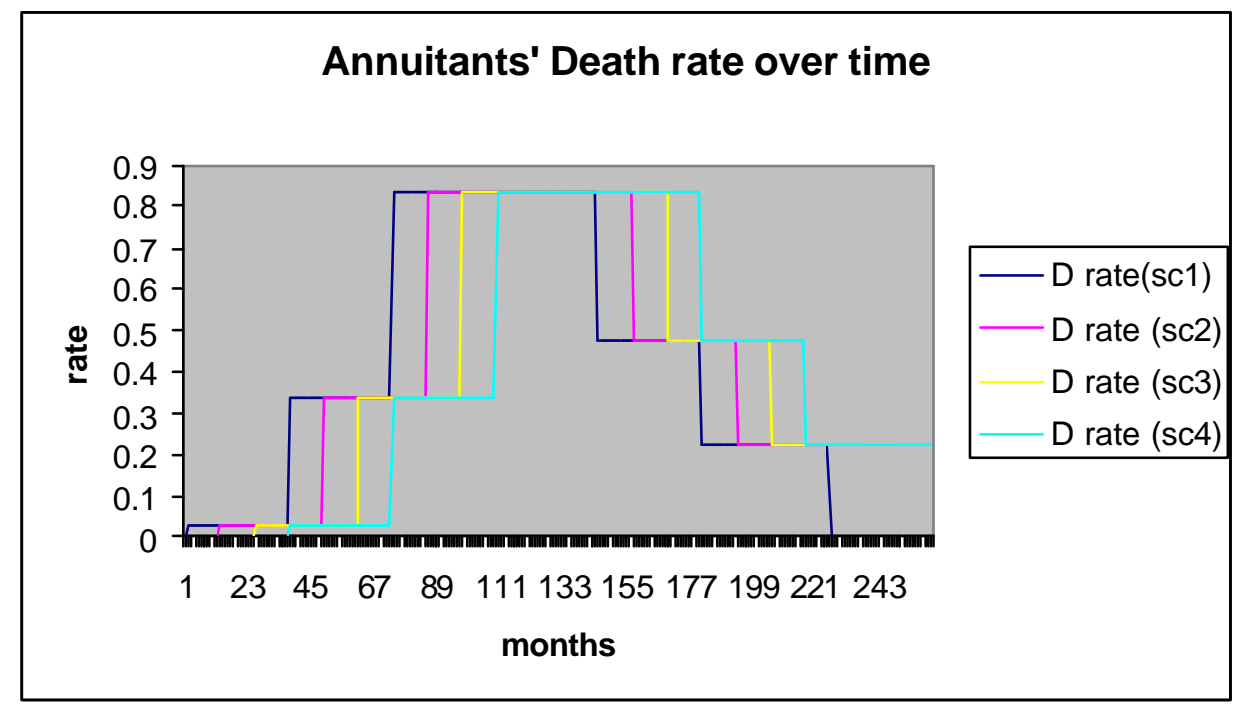

We next estimate the cash flows of the viagers under different simulated death rate scenarios and develop a valuation approach.

\section{VALUATION OF A POOL OF SECURITIZED VIAGER}

Insurance companies (and/or other financial institutions) investing in viagers, have the opportunity of financing their investments by securitizing pools of viagers. The viagerbacked-securities would receive cash flows generated by the underlying pool of viagers: the mortgage payments (negative cash flow) and the proceeds from the sale of properties at death of annuitants (positive cash flow). The faster annuitants die, the sooner the negative cash flows are eliminated. The main risk to investors in viager-backed-securities is that annuitants live above their life expectancy (longevity risk), therefore creating more negative cash flows. The number of viagers remaining in the pool, decreases over time as annuitants die. Equation (3) illustrates the number $m_{t}$ of viagers left in the pool at time $t$, computed by deducting the sum of deaths occurred over time, up to time $t$, from the original number $m_{0}$ of viagers.

$$
m_{t}=m_{0}-\stackrel{t}{?} d_{j=1}
$$

In Exhibit 5 we graph the number of viagers remaining in the pool under five different death rate scenarios, with scenario 5 being the one with the slower death rate.

\section{Exhibit 5}




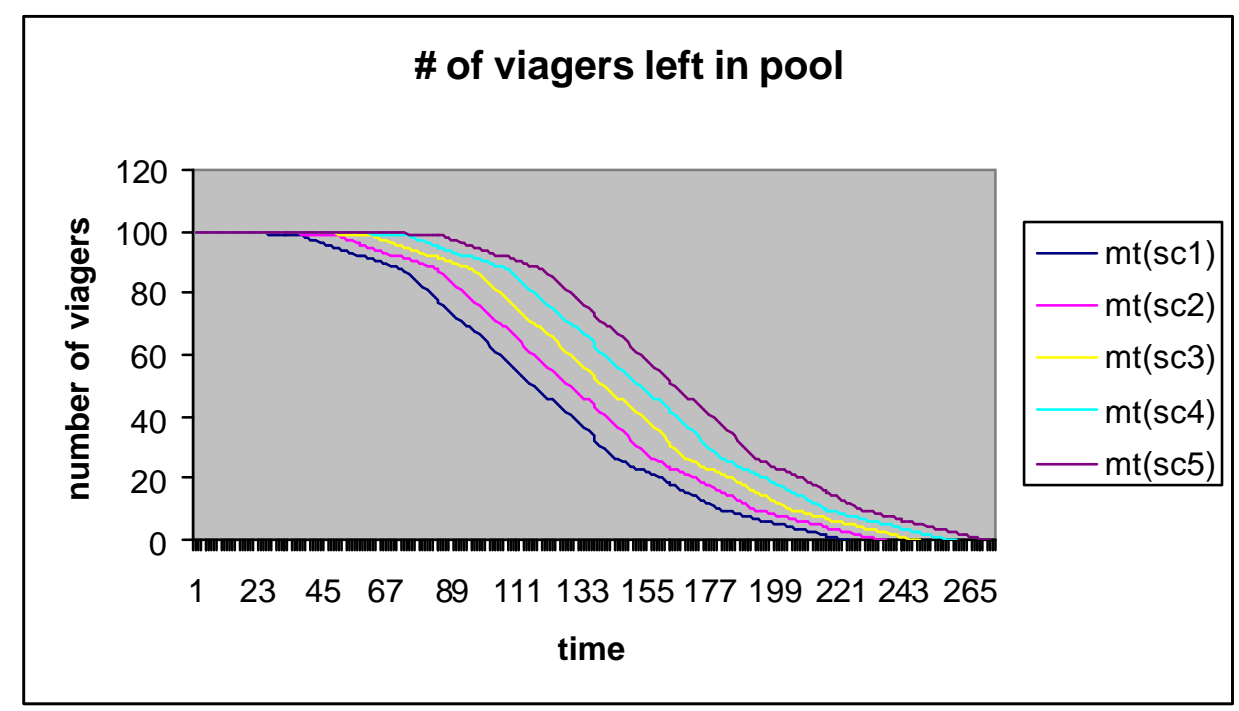

We defined in the appendix the monthly mortgage payments paid at the end of each month as $r$ and the market value of the property at the time of death as $v+a$.

The number of mortgage payments paid each month by the insurance companies that invested in viagers is a function of the number of viagers left in the pool at each point in time $\left(m_{t}\right)$; and the number of properties sold by the insurance companies at a price of $v+a$ is a function of the number of sellers dying in that period $\left(d_{t}\right)$. For simplicity we assume that at the time the viagers are pooled together, $r$ and $v+a$ are the same for each of the viagers, (the pool has seasoned viagers over different periods, with different bouquet amounts, different initial propertiy values, different annuitant ages).

Following, are the estimated cash flows at each point in time, $C F_{t}$, generated by the securitized pool of viagers. We graph the projected cash flows in Exhibit 6 under three different death scenarios.

$$
\begin{aligned}
& C F_{1}=-m_{0} r+d_{1}(v+a) \\
& C F_{2}=-m_{1} r+d_{2}(v+a) \\
& \cdot \\
& C F_{t}=-m_{t-1} r+d_{t}(v+a)
\end{aligned}
$$

\section{Exhibit 6}




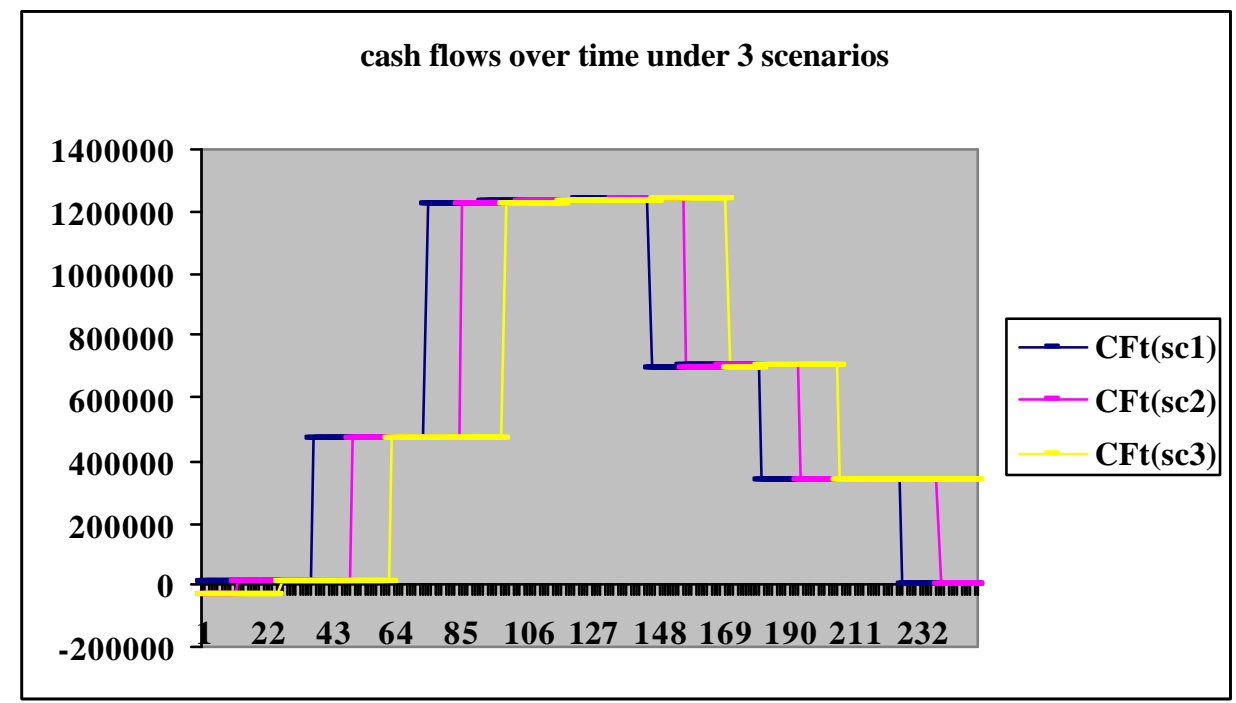

Under scenario 1 the cash flows are positive from the very beginning; under scenario 2 the cash flows are negative for the first twelve months and then as sellers start to die, the proceeds from the sale of properties create positive cash flows by outweighing the negative mortgage payments; under scenario 3 it is only after twenty four months that cash flows become positive.

Because of the nature of the pool of viagers with only few death occurring early on, and therefore creating negative cash flows early on, a liquidity facility should be provided to the issuer of the viager-backed securities.

The value of a securitized pool of viagers, $V$ (poolviagers), is then computed by summing the discounted cash flows to the present at the appropriate rate $k$ :

$$
V(\text { poolviagers })=?_{t=1}^{n} C F_{t} /(1+k)^{t}
$$

\section{Exhibit 7}




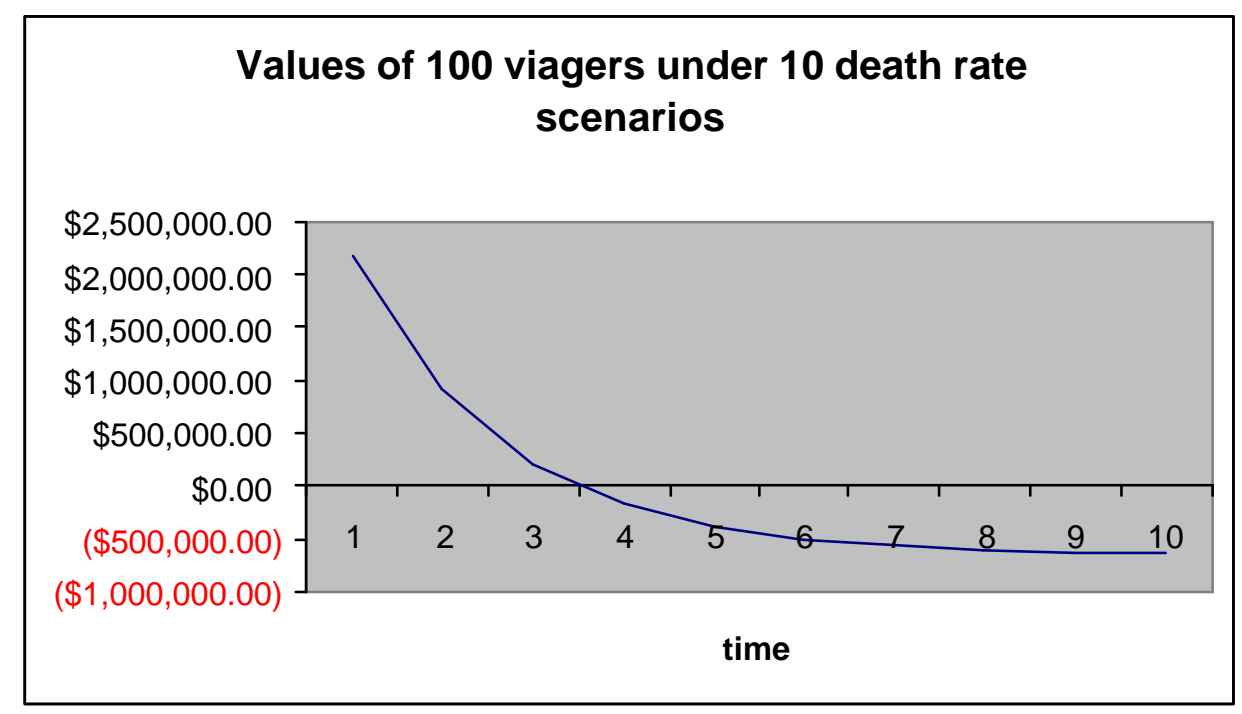

Exhibit 7 graphs the value of a pool of 100 viagers under ten different death rate scenarios. Scenario 1 is the base case, and each subsequent scenario shifts annuitants' death rate by twelve months.

The curve in Exhibit 7, will shift upward or downward, depending on the annuity level and the value of the properties at the time of the annuitants' death.

When securitizing viagers, it is possible to create different classes of securities from the underlying pool, where some classes will absorb most of the life extension risk, protecting investors in other classes. For example, a PAC class can be created with a band comprised between life expectancy of scenario 2 and that of scenario 5. As long as the life expectancies of the annuitants stay within that band, the investors in the PAC are totally protected from life extension risk, shifting it to the companion classes. This type of class has been named the targeted termination class (TTC), (Stone \& Zissu, 2006).

\section{LE-DURATION FOR SECURITIZED POOLS OF VIAGERS}

Stone \& Zissu (2006) introduced a new fixed-income securities type of duration, the "leduration". This le-duration is a useful tool for viaticles, life settlements, inverse mortgages, viagers, and we apply it next.

As shown in Exhibit 7, the value of a securitized portfolio of viagers decreases as annuitants live above life expectancy, and increases as they live below life expectancy. How sensitive is the value of these securities can be determined by the time-duration which we first derive for an individual viager as follows:

le-duration $=[\% d V($ viager $)] /[\% d t]$ 
le-duration $=[d V($ viager $) / d t][t / V($ viager $)]$,

which is the first derivative of the value of a viager relative to changes in $t$, subsequently multiplied by $t$ and divided by the value of the viager.

Equation (6) express the percentage change in value of a viager given a percentage change in life expectancy.

The value of an individual viager is:

$V($ viager $)=-r\left[1 /(1+k)^{1}+1 /(1+k)^{2}+\ldots . .+1 /(1+k)^{n}\right]+(v+a) /(1+k)^{n}$

Letting $a=1 /(1+k)$, equation (7) can be rewritten as:

$V($ viager $)=-(v+a)\left[a^{1}+a^{2}+\ldots . .+a^{t}\right]+(v+a) a^{t}$

Invoking the geometric series identity [Geometric Series Identity: $1+\mathrm{a}^{1}+\mathrm{a}^{2}+\ldots \ldots+\mathrm{a}^{\mathrm{n}}=$ $\left.\left(1-\mathrm{a}^{\mathrm{n}+1}\right) /(1-\mathrm{a})\right]$ and after rearranging, we obtain:

$V($ viager $)=\{[r /(1-a)]+(v+a)\} a^{t}$

We can now take the first derivative relative to changes in $t$ :

$d V($ viager $) / d t=[(v+a)+r /(1-a)] a^{t} \ln (a)$

and after multiplying the first derivative by $t$, dividing it by the value of the viager, and replacing $1 /(1+k)$ to $a$, we obtain the le-duration:

le-duration $=\operatorname{tln}[1 /(1+k)]$

The result of the le-duration is negative as we expected. The longer the annuitant lives above life expectancy, the less valuable is the viager.

Investors are interested in finding the percentage change in value of viagers relative to changes in time, rather than relative to percentage changes in time, so for practicality, we can develop the modified le-duration dividing the le-duration by $t$ :

modified le-duration $=\ln [1 /(1+k)]$ 
Investors in pools of viagers can evaluate the pool's sensitivity to life extension $d t$ using the modified le-duration of the pool:

$[\% d V($ poolviager $)]=d t \ln [1 /(1+k)]$

The percentage change in value of the pool $[\% d V$ (poolviager)] given a change in time due to life extension or reduction $(d t)$ is equal to the pool's modified le-duration $\ln [1 /(1+k)]$ multiplied by the life extension/reduction $d t$. The modified duration can be used for small changes in life extension or reduction. To find the percentage change in value of a securitized pool of viagers (or of other annuities with longevity risk) for large changes in life extension/reduction, we have to add the percentage change in value due to the $t$-convexity. We compute the $t$-convexity by taking the second derivative of the value of viager and obtain:

t-convexity:

$d^{2} V($ viager $) / d t^{2}=[(v+a)+r /(1-a)] a^{t} \ln (a)^{2}$

We have a positive convexity, which means that as an annuitant lives less than life expectancy, the value of the viager increases at an increasing rate.

\section{CONCLUSION}

The need for living benefits has led to the creation of many products with embedded annuities, and still more to be engineered. Longevity risk is of great concern to annuity writers. Life expectancy tables are changing rapidly and constantly. Mortality has been declining steadily over time, although not uniformly across different age ranges, as suggested by Renshaw, Haberman, and Hatzoupoulos (1996). Lin and Cox (2005) compute the percentage change in the present values of annuity payments under different simulated mortality shocks. From their numerical application we can see how sensitive securities with longevity risk can be to changes in life expectancies. We create a security with longevity risk backed by viagers, a French life annuity product. With the leduration, we are able to measure the sensitivity of these types of securities to changes in life expectancy of annuitants. Insurance companies selling life insurance policies are confronted with the risk of policy holders dying too soon (mortality risk). By investing in pools of securitized viagers, it is possible for insurance companies, to reduce mortality risk by adding longevity risk to their portfolios. The portfolio would be immunized against mortality shocks. 


\begin{abstract}
APPENDIX: THE VIAGER
The first step in a viager is to appraise the value $v$ of the property for sale. Next, the abattement d'occupation, $e$, must be deducted from the appraised value of the property. $e$, the abattement d'occupation is the value of the seller's occupied property during her/his expected remaining life $L E$, as a percentage of the value of the property at time $t=0$, time at which the property is being sold as a viager. For example a seventy year-old may sell his property, while still living in it with a 50\% abattement d'occupation, while an eighty year-old may have a 40\% abattement d'occupation. The accounting value $c$ of the occupied property is obtained by deducting the abattement d'occupation from the market value of the property:
\end{abstract}

$c=v(1-e)$

Notary fees, registration fees, the bouquet, $b$, and the rente, $r$, are all based on the accounting value of the occupied property, not on the appraised value of the property.

There are two components in the sale of the property as a viager, the bouquet and the rente. The bouquet is a lump sum that the purchaser pays at $\mathrm{t}=0$, and can vary from $15 \%$ to $35 \%$ of the accounting value. The rente (the term in French is misleading, because it is not a rent, but a mortgage payment) is computed as an annuity based on $B$, which is obtained from the difference between $c$ and $b$, and on the expected remaining life of the seller, using a discount rate $k$ (see article $1976 d u$ code civil). Basically the buyer has to make a down payment, which corresponds to the bouquet, and then has to make monthly mortgage payments on the remaining balance $B$, to the seller (the lender to the buyer) until the seller dies.

The monthly payments are calculated the same way as a mortgage payment, with the difference that a traditional mortgage has a predetermined life, whilst $r$, the monthly payment made to the seller, is a function of the seller's life expectancy $L E$ :

$r=(c-b) /\left[(1 / i)-1 /(1+i)^{L E}\right]$

where $b$ varies according to the age of the seller, $s$, and $i$ is the agreed mortgage rate. In general though it is higher the more senior the seller is, the expected remaining life being smaller, and based on the fact that mortgage payments $(r)$ are terminated at the death of the seller.

\title{
Example
}

$v=€ 1,000,000$
$s=80$ (woman)
$e=40 \%$

Using equation (1) we obtain the accounting value of $€ 600,000$ :

$c=€ 1,000,000(1-.4)=€ 600,000$ 
and if the agreed bouquet is in the amount of $€ 200,000$ then we have the remaining balance to be mortgaged equal to $€ 400,000$ :

$B=€ 600,000-€ 200,000=€ 400,000$

if $L E=9$ and $i=4 \%$

then the monthly mortgage payment would be in the amount of $€ 4416.39$.

When the seller dies, the new owner can sell the property at a market value of $v+a$, where $v$ was the market value of the property at the time the viager contract was signed by the two parties and a is the appreciation or depreciation of the property's value at the time of death, so it can be positive or negative. If death occurs very shortly after the contract was signed, it is possible to observe a decrease in the property's market value. In the long run though, it is more likely to observe appreciation in the property's value.

\section{References}

Bartel, Henry; Daly, Michael; Wrage, Peter, "Reverse Mortgages: Supplementary Retirement Income from Homeownership", The Journal of Risk and Insurance, Sept. 1980, v. 47, iss. 3, pp. 477-90.

Bhattacharga Jay, Goldman Dana, Sood Neeraj, "Price Regulation in Secondary Insurance Markets", The Journal of Risk and Insurance, 2004, Vol. 71, No.4, 643-675.

Chinloy, Peter, Megbolugbe, Isaac F., 'Reverse Mortgages: Contracting and Crossover Risk", Journal of the American Real Estate and Urban Economics Association, Summer 1994, v. 22, iss. 2, pp. 367-86.

Cowley, Alex; Cummins, J. David, "Securitization of Life Insurance Assets and Liabilities", Journal of Risk and Insurance, June 2005, v. 72, iss. 2, pp. 193-226.

Cummins, J.D., "Securitization of Life Insurance Assets and Liabilities", The Wharton Financial Institutions Center, 2004.

Goldstein Matthew, "Dying for 8\% - Investors Beware", Tavakoli Structured Finance, Inc., August 2004.

Ingraham Harold G. and Salani Sergio S., "Life Settlements as Viable Option", Journal of Financial Service Professionals, September 2004.

Klein, Linda S.; Sirmans, C. F., 'Reverse Mortgages and Prepayment Risk', Journal of the American Real Estate and Urban Economics Association, Summer 1994, v. 22, iss. 2, pp. 409-31. 
Lin, Yijia; Cox, Samuel H., "Securitization of Mortality Risks in Life Annuities", Journal of Risk and Insurance, June 2005, v. 72, iss. 2, pp. 227-52.

Milevsky, Moshe A., "The Implied Longevity Yield: A Note on Developing an Index for Life Annuities", Journal of Risk and Insurance, June 2005, v. 72, iss. 2, pp. 301-20.

Modu Emmanuel, 'Life Settlement Securitization”, A.M. Best Report October 18, 2004.

Prettys Solicitors, “An Introductory Guide to Buying Property in France”, June 2004.

Renshaw, A. E., S. Haberman, and P. Hatzoupoulos, "The Modeling of Recent Mortality Trends in United Kingdom Male Assured Lives", 1996, British Actuarial Journal, iss.2, pp. 449-477.

Richard Christine, "With \$70M Bond Deal, Wall St. Manages to Securitize Death", The Wall Street Journal, April 30, 2004.

Schapira, Steffen, "An Insurance Plan to Guarantee Reverse Mortgages", Comment; The Journal of Risk and Insurance, December 1990, v. 57, iss. 4, pp. 712-14.

Stone Charles A. and Zissu Anne, "Risk Management - Risk Measurement" Letter from the Editors, The Financier, Vol.3, No. 4 \& 5, 1996.

Stone Charles A. and Zissu Anne, "Securitization of Senior Life Settlements: Managing Extension Risk', Journal of Derivatives, Spring 2006.

Taglich Brothers, Inc. Research Report on Life Partners Holdings, Inc. December 2004.

Weinrobe, Maurice, "An Insurance Plan to Guarantee Reverse Mortgages", The Journal of Risk and Insurance, December 1988, v. 55, iss. 4, pp. 644-59. 